\title{
A MEDIAÇÃO E O PROTAGONISMO DAS FAMÍLIAS NO DIREITO DE FAMÍLIA COM AS CONTRIBUIÇÕES DE PAULO FREIRE
}

\author{
Virginia Grace Martins de Oliveira ${ }^{1}$
}

\begin{abstract}
Resumo
Este artigo analisa se a mediação pode viabilizar o protagonismo das famílias no Direito de Família. Para isto, visa construir a ideia de protagonismo sob a óptica de Paulo Freire, pois entende-se, que o autor pode contribuir com concepções sobre autonomia e liberdade. A pesquisa utiliza-se da técnica de pesquisa bibliográfica e documental e do método dedutivo de abordagem, cujo referencial teórico principal, mas não isolado, são as concepções de Freire. Conclui que a mediação pode viabilizar o protagonismo das famílias, desde que se respeite os princípios constitucionais e infraconstitucionais e diretrizes regentes alinhadas à prática da mediação.
\end{abstract}

Palavras Chave: Mediação. Direito de Família. Protagonismo. Código de Processo Civil. Paulo Freire.

\section{THE MEDIATION AND PROTAGONISM OF THE FAMILIES IN FAMILY LAW WITH THE CONTRIBUITONS OF PAULO FREIRE}

\begin{abstract}
This article analyzes if the mediation can enable the protagonism of families in family law. For this, it aims to build the idea of protagonism from the perspective of Paulo Freire, as it is understood that the author can contribute with conceptions about autonomy and liberty. The research uses the technique of bibliographic and documentary and the deductive method of approach, whose main theoretical reference, but not isolated, are Freire's conceptions. It concludes that mediation can enable the protagonism of families, if the constitutional and infraconstitutional principles and legal guidelines aligned with the practice of mediation can be respected.
\end{abstract}

Keywords: Medation. Family law. Protagonism. Civil Procedure Code. Paulo Freire

\section{INTRODUÇÃO}

No Brasil constata-se desde o final do século XX uma busca pela desjudicialização de conflitos, o que é demonstrado pela publicação da Lei de Arbitragem, a Lei n. 9.307/96. E

\footnotetext{
${ }^{1}$ Mestre em Direito, com ênfase em Justiça e o Paradigma da Eficiência, pela Universidade Nove de Julho (UNINOVE). Possui especialização em Direito de Família e Sucessões pela Escola Paulista de Direito (EPD). É autora de diversos artigos na área de Formas Consensuais de Solução de Conflitos.

Endereço eletrônico: virginiagrace@gmail.com
} 
posteriormente, acompanhando esse movimento, houve a publicação da Resolução n. 125/10 pelo Conselho Nacional de Justiça (CNJ), que impulsionou a busca pela desjudicialização de conflitos, ao mesmo tempo em que se inicia uma solidificação da autocomposição de conflitos no país.

A Resolução não somente trouxe diretrizes regentes para a conciliação e a mediação ${ }^{2}$ como os instrumentos autocompositivos de resolução de conflitos a serem adotados pelo Brasil, mas também implementou uma política pública de tratamento adequado de conflitos de interesse.

E seguindo esse trajeto, em 2015, houve as publicações da Lei n.13.140/15, a Lei de mediação e do Novo Código de Processo Civil (NCPC) instituído pela Lei n. 13.105/15, que também determina regras sobre os meios autocompositivos adotados pelo Brasil e concretizados por meio da mencionada Resolução. Os dispositivos legais admitem a utilização da mediação nos âmbitos judicial e extrajudicial

O NCPC incentiva claramente a utilização da solução consensual de conflitos de interesse, já que dispõe em vários artigos sobre esse tema, como se extrai do art. $3^{\circ}, \S 3^{\circ}$, de que "a conciliação e a mediação, bem como outros meios consensuais de solução de conflitos deverão ser estimulados pelos profissionais do Direito, inclusive no curso do processo civil". Outra disposição, se extrai do art. 695, que faz parte dos procedimentos especiais atinentes ao Direito de Família, ao determinar "a ordenação da citação pelo juiz para que a parte compareça a audiência de mediação e conciliação".

Denota-se que a inserção da solução consensual em ações especiais, como é o caso das ações de família, confere à solução consensual um caráter específico que não dispensa estudos e reflexões sobre o contexto, com o objetivo de analisar e elucidar as especificidades, potencialidades, possibilidades e tendências do trabalho autocompositivo nessa área específica, como é o Direito de Família, que não prescinde de estudos interdisciplinares.

Isto porque, no tocante a área familiar no Direito, predomina a proteção à pessoa humana. E o momento histórico-social atual expõe modificações nas estruturas e formação das famílias, o que por conseguinte causa alterações nas relações humanas que se formam nesse meio. E o Direito deve acompanhar as inovações e especificidades dessa área, já que possui a função de estudar as regras que regulam as relações humanas na sociedade.

\footnotetext{
${ }^{2}$ Apesar da Política Pública de tratamento adequado de conflitos tratar tanto da conciliação quanto da mediação, esta pesquisa dedica-se a analisar o instituto da mediação.
} 
Dessa forma, este artigo tem por objetivo analisar a utilização da mediação no Direito de Família, como uma área que possui particularidades, enfocando a pertinência e se a mediação, um instrumento consensual de resolução de conflitos, que possui definição, estrutura e potencialidades próprias pode viabilizar às partes oportunidades para que sejam protagonistas em relação as suas escolhas e no direcionamento de suas vidas, como sujeitos de seus próprios destinos, visando o bem comum.

Para isto, aborda-se o tema de forma interdisciplinar, visando delimitar e construir a noção de protagonismo da pessoa humana sob a óptica de Paulo Freire, pois no entendimento desta pesquisa, o autor pode contribuir para as reflexões sobre o tema, já que concebe a ação humana como algo que pode transformar a realidade e que por isto, o homem pode ser sujeito de seu próprio destino ao agir de forma autônoma sobre a realidade que o cerca.

A pesquisa utiliza-se da técnica de pesquisa bibliográfica e documental e do método dedutivo de abordagem, cujo referencial teórico principal, mas não isolado, é baseado em concepções preconizadas por Paulo Freire, como mencionado, no tocante a ação humana sobre o meio circundante que eleva o ser humano a ser o principal sujeito ativo de suas ações, que no entendimento desta pesquisa, centra-se nessa concepção, a ideia de protagonismo da pessoa humana.

Desse modo, este trabalho aborda a ideia de protagonismo da pessoa humana, com as contribuições de Paulo Freire, inseridas na mediação, com o fim de verificar se o instrumento pode viabilizar o protagonismo da ação humana na condução de seus destinos.

E insere-se esta abordagem sobre a mediação nas ações de família, estas, com suas particularidades que lhe conferem um significado e tratamento específicos no Direito que resultaram na construção de um ramo peculiar denominado Direito de Família.

\section{O PROTAGONISMO DA PESSOA HUMANA SOB A ÓPTICA DE PAULO FREIRE}

A presente análise tem por escopo delimitar e construir a noção de protagonismo da pessoa humana perante as concepções construídas por Paulo Freire, um educador e filósofo brasileiro reconhecido internacionalmente, que traz ideias construídas no tocante a formação humana pautadas na autonomia, liberdade e transformação da realidade. 
O protagonismo da pessoa humana é um tema que envolve uma abrangência de concepções $^{3}$. A ideia de ser o agente principal sobre atos e fatos contribui para o presente estudo, mas o que se pretende é extrapolar o campo de atos e fatos isolados e elevar a condição de ser agente principal para o âmbito da convivência humana em sociedade.

E como a ideia de protagonismo que se constrói no presente estudo baseia-se nas concepções construídas por Freire, faz-se necessário refletir a respeito de liberdade e autonomia, que são temas abordados pelo autor e que contribuem para formar a ideia de protagonismo da pessoa humana em diversos contextos.

A liberdade é um vocábulo que possui inúmeros significados ${ }^{4}$. E se tornou objeto de reivindicações pelo homem em vários momentos históricos, assumindo nestes diferentes contextos sentidos variados (OLIVEIRA, 2015, p. 16-17).

Para Hanna Arendt ([20--?], p. 11),

\begin{abstract}
A liberdade de movimento é também a condição indispensável para a ação, e é na ação que os homens primeiramente experimentam a liberdade no mundo. Quando os homens são privados do espaço público - que é constituído pela ação conjunta e a seguir se preenche, de acordo consigo mesmo, com os acontecimentos e estórias que se desenvolvem em história-, recolhem-se para sua liberdade de pensamento.
\end{abstract}

Como se vê, a autora aborda a liberdade de movimento e de pensamento e não deixa de mencionar a "ação conjunta" pertinente ao espaço público.

A autonomia possui uma abordagem pensada por Jean Piaget e discutida pelas autoras Kamii e Declarck (1988, p. 68) que asseveram, “autonomia significa ser governado por si mesmo. É o oposto de heteronomia, que quer dizer ser governado por outra pessoa".

As autoras consideram também os aspectos moral e intelectual da autonomia. $\mathrm{O}$ primeiro se refere as construções das opiniões próprias que a pessoa humana realiza embasando-se em seus valores morais. Ao segundo atribui-se o agir da pessoa humana segundo suas opiniões (KAMII; DECLARCK, 1988, p. 68 e 74).

\footnotetext{
${ }^{3}$ O dicionário Houaiss (2009, p. 1565) define protagonizar como, "1 interpretar o papel da personagem principal 2 ser o agente principal de um ato, um acontecimento".

${ }^{4}$ No dicionário Houaiss consta: 1. grau de independência legítimo que um cidadão, um povo ou uma nação elege como valor supremo, como ideal 2. Derivação por extensão de sentido. Conjunto de direitos reconhecidos ao indivíduo, isoladamente ou em grupo, em face da autoridade política e perante o Estado; poder que tem o cidadão de exercer a sua vontade dentro dos limites que lhe faculta a lei. [...] 6. autonomia, independência, soberania (HOUAISS, 2009, p. 1175).
} 
A abordagem de Paulo Freire sobre liberdade e autonomia evidencia a situação de opressão vivida por homens e mulheres. Esta opressão se dá entre, os denominados pelo autor, de opressores e oprimidos. A situação de ser oprimido se revela na falta de liberdade e autonomia, "no ser menos" (FREIRE, 2014, p. 41). E a busca da liberdade é a restauração da humanidade tanto para os oprimidos quanto para os opressores, que são aqueles que submetem os oprimidos ao "ser menos" e distorcem a situação do "ser mais" (FREIRE, 2014, p. 41).

Percebe-se nessa abordagem que o autor demonstra a separação que há na sociedade, entre aqueles que possuem voz e os que não a possuem, estes são os oprimidos, a quem não cabe falar, criar, opinar ou decidir, o que lhes resta é aceitar o que os opressores pensam e decidem por e para eles. Entende-se que esse panorama ocorre numa sociedade onde existe a cultura da dominação, o que impede a participação dos oprimidos na realidade social, política, econômica e histórica.

Portanto, os oprimidos vivem em situação de dependência em relação aos opressores. Esta relação faz com que o oprimido não exerça sua autonomia e liberdade, posto que se submete às ordens, organização e ideias dos opressores que, por sua vez, direcionam suas vidas. Esta dependência subjacente à relação existente entre opressor e oprimido é exposta pelo autor como "dependência emocional", porque o oprimido, que muitas vezes pode ser, por exemplo, um camponês ou um operário inserido na cultura da dominação apresenta comportamentos peculiares (FREIRE, 2014, p.67-71). Os comportamentos ou características peculiares refletem todo o arcabouço de dominação existente e se traduzem para o autor em formas de comportamento. O oprimido vive e exterioriza a dominação em que vive, de forma não deliberada e inconsciente (FREIRE, 2014, p.67-68). E assim Paulo Freire (2014, p. 67) explicita que,

\footnotetext{
Uma destas de que já falamos rapidamente, é a dualidade existencial dos oprimidos que, "hospedando" o opressor, cuja "sombra" eles "introjetam", são eles e ao mesmo tempo são o outro. Daí que, quase sempre, enquanto não chegam a localizar o opressor concretamente, como também enquanto não cheguem a ser "consciência para si", assumam atitudes fatalistas em face da situação concretas de opressão em que estão. ${ }^{5}$
}

\footnotetext{
${ }^{5}$ Texto da nota explicativa do autor presente na obra referenciada: "O camponês, que é um dependente, começa a ter ânimo para superar sua dependência quando se dá conta de sua dependência. Antes disto, segue o patrão e diz quase sempre: 'Que posso fazer, se sou um camponês?'- Palavras de um camponês durante entrevista com o autor no Chile.
} 
Outra característica peculiar dos oprimidos exposta pelo autor é a "autodesvalia", que resulta da introjeção do opressor dentro do oprimido a ponto de provocar nestes um desejo de ser igual ao opressor, de imitá-lo, de seguir seus rumos, suas escolhas, ideias e comportamentos (FREIRE, 2014, p. 68). Nesta imitação, propaga-se essa situação de dominação até entre os iguais, ou seja, por meio de agressões entre os companheiros oprimidos $^{6}$.

O mencionado autor explicita (2014, p.69), "De tanto ouvirem de si mesmos que são incapazes, que não sabem nada, que não podem saber, que são enfermos, indolentes, que não produzem em virtude de tudo isto, terminam por se convencer de sua 'incapacidade"'. ${ }^{7}$ Essas características peculiares dos oprimidos traduzem o que Freire $(2014$, p. 71), chama de "visão inautêntica de si e do mundo".

Paulo Freire propõe a superação desta relação de subjugação entre opressor e oprimido por meio da libertação que se concretiza na "reflexão e ação dos homens sobre o mundo para transformá-lo" (FREIRE, 2014, p. 52). Mas, tanto a reflexão como a ação precisam saber enfrentar as características peculiares que surgem nos oprimidos provocadas pela estrutura da dominação, porque nesse desejo do oprimido em ser igual ao opressor, o caminho para a conscientização pode ser difícil, pois é preciso que o oprimido se reconheça como Ser com capacidades, deslocado dessa relação de dominação.

Por isto, o autor propõe uma "ação política" junto aos oprimidos que ele denomina de "ação cultural para a liberdade" com o fim de superar a "visão inautêntica" do mundo (FREIRE, 2014, p.73). Nessa ação também denominada por ele de "ação libertadora", há ênfase na ideia de que os oprimidos devem ser vistos como sujeitos e não como objetos, ou seja, serem apenas os destinatários de decisões e ações, mas os sujeitos das ações para si próprios (FREIRE, 2014, p. 74). O autor assevera (2014, p. 75), “A não ser que se pretenda fazer para eles a transformação, e não com eles".

Denota-se nas propostas de Freire o enfoque na ação do indivíduo que se traduz por meio de sua autonomia que é o exercício de suas decisões, opiniões, criações, ações, construções e participações, isto é ser autônomo e exercer a liberdade. Enfim, segundo

\footnotetext{
${ }^{6}$ Segundo Paulo Freire (2014, p. 68), sobre essa agressão: "Ao agredirem seus companheiros oprimidos estarão agredindo neles, indiretamente, o opressor também "hospedado" neles e nos outros".

${ }^{7}$ Consta como nota de rodapé do autor referente ao trecho citado: "Cf. A este respeito o livro citado de Albert Memmi”.
} 
Oliveira (2015, p. 23) Freire enfatiza que, "a autonomia é condição para o exercício da liberdade com ética". A ideia de libertar-se da opressão e dominação que o autor constrói é ampla, pois não se refere somente a aliviar a fome ou permitir o exercício de direitos no contexto opressivo, mesmo que esse contexto tenha sido alterado por meio de leis, pois entende-se que não basta alterar leis e oferecer direitos (FREIRE, 2014, p.76). Essa ideia é explicitada brilhantemente pelo autor (2014, p. 76) ao expressar que,

\begin{abstract}
Desde o começo da luta pela humanização, pela superação da contradição opressoroprimidos, é preciso que eles se convençam de que esta luta exige deles, a partir do momento em que a aceitam, a sua responsabilidade total. É que esta luta não se justifica apenas em que passem a ter liberdade para comer, mas "liberdade para criar e construir, para admirar e aventurar-se". Tal liberdade requer que o indivíduo seja ativo e responsável, não um escravo nem uma peça bem alimentada da máquina. Não basta que os homens não sejam escravos; se as condições sociais fomentam a existência de autômatos, o resultado não é amor à vida, mas o amor à morte. ${ }^{8}$ Os oprimidos que se "formam" no amor à morte, que caracteriza o clima de opressão, devem encontrar, na sua luta, o caminho do amor à vida, que não está apenas no comer mais, se bem que o implique também e dele não possa prescindir.
\end{abstract}

Entende-se que, para Freire, ser sujeito ativo implica em ser responsável por suas ações, depois de aceitar a luta para superar a opressão e a contradição existente nessa situação, conforme exposto neste estudo. É imperioso notar a existência das ideias de aceitação da luta e a de não ser um ser autômato que vive sem compreender a vida com suas relações sociais. E viver é compreender a realidade e transformá-la, utilizando-se de sua liberdade com responsabilidade, no sentido de superar a opressão que mantém os oprimidos sem vida, isto é, sem ação sobre a vida FREIRE, 2014, p. 76).

Entende-se, baseando-se nas ideias construídas por Paulo Freire que liberdade é primeiramente poder aceitar ou não a luta, se engajar, agir para além de reivindicar direitos e necessidades básicas para viver, mas é o de ser autor de sua história, de sua vida, participando das propostas que concretizam direitos, criando, escolhendo e construindo ou reconstruindo a realidade com responsabilidade. Nesse sentido, Paulo Freire (2000, p. 122-123) explicita,

Quando falo em educação como intervenção me refiro tanto à que aspira a mudanças radicais na sociedade, no campo da economia, das relações humanas, da propriedade, do direito ao trabalho, à terra, à educação, à saúde, quanto à que, pelo contrário, reacionariamente pretende imobilizar a História e manter a ordem injusta.

\footnotetext{
${ }^{8}$ Consta na obra a seguinte nota de rodapé do autor: "Fromm, op. cit., p.54-5."
} 
Como se vê, a ideia do autor é situar o indivíduo como um ser ativo até mesmo para desmantelar a ordem injusta. Denota-se o uso do poder decisório da pessoa humana sobre a realidade circundante para transformá-la. Desta forma, como assevera Paulo Freire (1967, p. $43)$,

\begin{abstract}
A partir das relações do homem com a realidade, resultantes de estar com ela e de estar nela, pelos atos de criação, recriação e decisão, vai ele dinamizando o seu mundo. Vai humanizando-a. Vai acrescentando a ela algo de que ele mesmo é o fazedor. Vai temporalizando os espaços geográficos. Faz cultura. E é ainda o jogo destas relações do homem com o mundo e do homem com os homens, desafiado e respondendo ao desafio, alterando, criando, que não permite a imobilidade a não ser em ternos (sic) de relativa preponderância, nem das sociedades e nem das culturas. E, na medida em que se cria, recria e decide, vão se conformando as épocas históricas. É também criando, recriando e decidindo que o homem deve participar destas épocas.
\end{abstract}

Assim, entende-se que o exercício consciente das decisões possibilita a concretude da autonomia do indivíduo para Freire. E isto, na concepção deste autor, é a expressão da liberdade do indivíduo (OLIVEIRA, 2015, p. 43). E pensando-se no agir do indivíduo na sociedade, vislumbra-se que as ideias de Paulo Freire sobre a autonomia e liberdade não se limitam às ações na esfera individual, pois prosseguem para a esfera social como destino da ação dos indivíduos. Entende-se que a atuação individual tem por objetivo modificar a realidade visando o bem comum.

Desse modo, entende-se que as abordagens propostas por Paulo Freire são mais assertivas e adequadas para a presente pesquisa, pois reúne as concepções expostas pelos autores mencionados atinentes a ação conjunta dos indivíduos como espaço de experiência da liberdade, bem como, sobre a relação que há entre opinião e ação no tocante a autonomia. E o autor segue além, pois situa autonomia e liberdade como os caminhos para a libertação da opressão e por conseguinte de transformação da realidade.

É nesse sentido que este estudo entende que a ideia de protagonismo da pessoa humana, segundo Paulo Freire, se assenta no exercício do poder decisório, no agir, na participação do indivíduo na sociedade com o fim de construí-la em conjunto com outros indivíduos, como sujeitos protagonistas que podem intervir na realidade circundante, desmantelando a ordem injusta, assumindo a responsabilidade por suas decisões e não como meros expectadores e destinatários de ideias, vontades e ações de uma determinada classe social ou grupos que detenham o poder econômico, político e social. 


\section{MEDIAÇÃO: CONCEITO E PARTICULARIDADES}

O Brasil percorre um trajeto desde o final do século XX que busca a desjudicialização dos conflitos e a pacificação social. Esse trajeto chegou ao seu ápice com a publicação da Resolução n. 125/10 do CNJ, que trouxe diretrizes regentes à autocomposição no país e adotou como meios autocompositivos, a conciliação e a mediação.

A mediação é um meio consensual de solução de conflitos. "O procedimento é conduzido por um terceiro imparcial e isento, que possui como função, auxiliar ou estimular as partes a alcançar a solução do conflito no qual estão envolvidas". Como se extrai da Lei 13.140/15, essa definição está determinada no art. $1^{\text {o }}$, parágrafo único. E como pode-se observar, a definição enfatiza que o terceiro imparcial não possui poder decisório, por isto, a solução é autocompositiva, baseada essencialmente no consenso das partes.

Antes da edição da mencionada Lei, a doutrina jurídica brasileira já debatia sobre a definição do mecanismo que o erigiu como um meio de solução de conflitos que privilegia a intervenção de um terceiro sem poder decisório. Nesse sentido, Calmon (2013, p. 113) ilustra, “[...] mediação é a intervenção de um terceiro imparcial e neutro, sem qualquer poder de decisão, para ajudar os envolvidos em um conflito [...]”.

Para José Maria Rossani Garcez (2004, p. 39), “nela, um terceiro, imparcial, auxilia as partes a chegarem, elas próprias, a um acordo entre si, através de um processo estruturado".

As autoras Zaparolli e Krähenbühl (2012, p. 89) definem a atividade como,

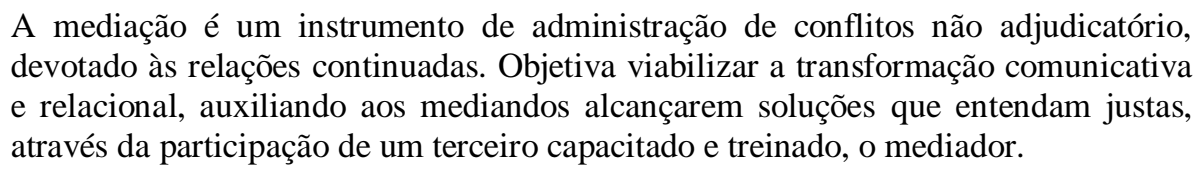

Como se vê, a legislação recepcionou a definição anteriormente construída pela doutrina. Além disso, como se extrai da Lei n. 13.140/15, há os princípios que envolverão o procedimento, entre eles, se encontra a "autonomia da vontade das partes". Entende-se que este princípio denota o enfoque nas decisões emanadas pela vontade das partes, como um eixo norteador para o mecanismo. E sobre a importância deste princípio, a autora Fernanda Tartuce (2018, p. 204), ilustra,

A autonomia da vontade implica o reconhecimento também do princípio da liberdade: os participantes da mediação têm o poder de definir e protagonizar o 
encaminhamento da controvérsia, o que inclui desde a opção pela adoção do método compositivo até a responsabilidade pelo resultado final.

Desse modo, observa-se que a definição e a estrutura própria da mediação possibilitaram para as pesquisas e estudos, centrados nessa temática, explorações no que tange às particularidades, potencialidades e tendências do instrumento, pois observa-se o caráter interdisciplinar que a mediação possui, já que lida com seres humanos envolvidos em seus conflitos e que pode lhes proporcionar o exercício do poder decisório, identificação dos problemas e soluções, bem como, o encontro de diferentes pontos de vista sobre um fato. E por isto, não se descarta a necessidade de conceber a mediação sob a contribuição de diversas áreas do conhecimento.

Nesse sentido, Zaparolli e Krähenbühl (2012, p. 88) explicitam, “a contribuição das diferentes áreas do conhecimento proporcionou uma sólida base à mediação, que se utiliza de aporte teórico e instrumental de origem em outras searas, adaptando seus fundamentos teóricos e técnicos à prática".

Além disso, a autora Fernanda Tartuce (2018, p. 189), ao mencionar que a mediação pode proporcionar um "espaço qualificado de conversação", demonstra o caráter sofisticado do instrumento que explora a comunicação entre os envolvidos visando a solução conjunta do conflito.

Tais fatores demonstram as particularidades e a complexidade do instrumento que não lhe permite ser visto como algo que tende somente para a solução de um conflito pontual, ou promover a desjudicialização, mas que além disso, viabiliza resolver impasses já existentes numa relação continuada ${ }^{9}$. Zaparolli e Krähenbühl $(2012$, p. 89) a respeito da complexidade da mediação, esclarecem que,

O processo de mediação é complexo e contextual, podendo comportar os conceitos de resolução de conflitos, acordo, comunicação, transformação de significados de contexto e de relação. Não deve ser visto, porém, de forma simplista, atado a apenas um desses conceitos, à obtenção de acordos ou solução de disputas e problemas pontuais.

Dessa forma, diante das particularidades e potencialidades do instrumento mediação, foram construídos modelos e concepções que enfocam questões relativas às relações humanas, subjacentes ao procedimento. Dentre eles, se encontra o modelo construído por

\footnotetext{
${ }^{9}$ Vale ressaltar que este entendimento foi recepcionado pela Lei n. 13.105/15, o Novo Código de Processo Civil, como se pode extrair do art. $165, \S 3^{\circ}$.
} 
Folger e Bush (1999, p. 85 e 86), denominado, "abordagem transformativa" que se pauta na "transformação do ambiente social - de um ambiente de luta individual adversária para um ambiente de engajamento cooperativo na formação de elos comuns e busca de melhoria mútua" ${ }^{\prime 10}$.

Nas palavras de Zaparolli e Krähenbühl (2012, p. 89), “o modelo transformativo, idealizado por Bush e Folger (1994), [...] pressupõe um aumento no protagonismo dos mediandos, em que eles próprios percebam-se como partes integrantes do conflito e vislumbrem a possibilidade de sua administração”. Percebe-se que nesta abordagem, há uma relação entre o poder de administrar o próprio conflito e ser o protagonista de seu destino. E, isto implica em obter independência e autonomia. Por isto, nesta visão, não é fundamental a resolução do conflito pontual, mas sim o caminho percorrido que possibilite às partes expressarem a autonomia por meio da administração do próprio conflito.

Por isto, a prática da mediação pressupõe respeito ao princípio da autonomia da vontade. E para isto, é imprescindível que haja um alinhamento entre a prática, diretrizes regentes e os estudos teóricos que abordam as potencialidades do instrumento, como a "abordagem transformativa" proposta por Folger e Bush.

\section{O DIREITO DE FAMÍLIA: DEFINIÇÃO E PARTICULARIDADES}

O Direito de Família é considerado um ramo específico do Direito Civil. E como o Direito é a ciência que possui a função de estudar as regras que normatizam a vida em sociedade, poder-se-ia dizer que o Direito de Família possui a função de estudar as regras que normatizam a convivência humana no âmbito familiar. Contudo, essa definição pode se alongar para outras definições, como, por exemplo, o que é família ou organização familiar.

Desse modo, percebe-se que definir Direito de Família não é tarefa simples, posto que atualmente há distintos entendimentos sobre o que é família, ou sobre o que é organização familiar. E para isto é preciso utilizar parâmetros que auxiliem na definição.

Nesse sentido, Washington de Barros Monteiro e Regina Beatriz Tavares da Silva (2016, p. 23) afirmam que, "difícil se torna definir o direito de família sem incidir num vício de lógica. Realmente, esse ramo do direito civil, de modo geral, disciplina a organização da

\footnotetext{
${ }^{10}$ Nesse sentido, Fernanda Tartuce (2018, p. 205) explana, "Na perspectiva transformativa, [...] pode se alcançar uma sorte de evolução moral ou "transformação" por meio do aprimoramento da autonomia".
} 
família; todavia, quem assim se expresse está a conceituá-lo com o próprio objeto a definirse".

A Constituição da República Federativa do Brasil de 1988 (CRFB/88) apresenta um parâmetro, como se pode extrair do art. 226, alçando a família como, "base da sociedade" e a "união estável entre homem e mulher reconhecida como entidade familiar", bem como, "a comunidade formada pelos pais e descendentes", também considerada uma entidade familiar.

No entanto, observa-se uma evolução nos costumes que deu origem a novos tipos de relações familiares, que se baseiam também nos laços afetivos, além dos consanguíneos (LÔBO, 2016, p. 120).

O Código Civil de 2002 (CC/02) apresenta um parâmetro, explicado por Flavio Tartuce (2017, p. 1218) ao ilustrar que,

[...] o Direito de Família pode ser conceituado como um sendo o ramo do Direito Civil que tem como conteúdo o estudo dos seguintes institutos: a) casamento; b) união estável; c) relações de parentesco; d) filiação; e) alimentos; f0 bem de família; g) tutela, curatela e guarda. Além desse conteúdo, acrescente-se a investigação das novas manifestações familiares.

O CC/02 divide o ramo em dois livros, um se refere ao Direito Existencial da Família, que se baseia na pessoa humana e o outro diz respeito ao Direito Patrimonial da Família, que enfoca o patrimônio (TARTUCE, 2017, p. 1218).

Na concepção de Giselda Maria Fernandes Novaes Hironaka (2016, p. 62),

Destarte, Direito de Família é o ramo do conhecimento que visa justificar as relações de família consanguínea, civil ou afetiva sob as orientações dos princípios constitucionais de proteção à dignidade da pessoa humana, de solidariedade familiar, de igualdade entre filhos, de igualdade entre cônjuges e companheiros, de afetividade e de função social da família, entre outros corolários desses.

Como se pôde observar, a definição de Direito de Família está vinculada a ideia de regramento sobre a formação e relações inseridas nas entidades familiares. Entretanto, foi observado que houve uma evolução nos costumes, o que por si só pode acabar por afetar o regramento atinente ao direito. E além do regramento apresentado pelo CC/02 que se divide entre Direito Existencial e Patrimonial, há os princípios constitucionais que visam orientar o Direito de Família. 
Denota-se que, regras constantes na letra da lei, não são suficientes para definir, orientar e embasar a constituição familiar ou impor-lhes limites ou dizer-lhes o direito. Como ensina com maestria, Giselda Maria Fernandes Novaes Hironaka (2016, p. 61) ao afirmar que,

\begin{abstract}
Não se nega que algumas regras podem tentar (e até conseguir) delinear o que em casos específicos é direito, porém jamais conseguirão prendê-lo no limite das suas frias letras, como se nada existisse ou fosse "direito" para além dela. O Direito de Família não externa objeto. É o próprio exercício vida. Não é produto do legislador ou das decisões judiciais, posto situação e relação humana das mais íntimas, não aquelas vulgares cujo condão é a pura vontade, mas sim daquelas ligadas pelo sangue ou pelo afeto.
\end{abstract}

Entende-se que os estudos sobre Direito de Família necessitam debruçar-se sobre os princípios constitucionais, pois o foco no Direito de Família é a pessoa humana, apesar de existir o regramento sobre o patrimônio da família. Entretanto, este regramento não objetiva regrar o patrimônio propriamente dito, mas visa proteger a família. Flavio Tartuce (2017, p. 1219) ilustra brilhantemente esta ideia ao afirmar que, "perde o patrimônio o papel de ator principal e se torna mero coadjuvante".

Quanto aos estudos dos princípios constitucionais inseridos no Direito de Família, o presente estudo apresenta a contribuição de Paulo Lôbo (2016, p. 110) que brilhantemente os agrupou de forma didática a saber, "PRINCÍPIOS FUNDAMENTAIS I- Dignidade da pessoa humana; II-Solidariedade; PRINCÍPIOS GERAIS III-Igualdade; IV-Liberdade; VAfetividade; VI-Convivência familiar; VII-Melhor interesse a criança; VIII-Responsabilidade familiar".

Os dois primeiros princípios são considerados pela doutrina jurídica como estruturantes da Constituição e de toda a ordem jurídica brasileira (LÔBO, 2016, p.110). E, para cumprir com as finalidades do presente estudo, realizar-se-á uma exposição sobre o princípio constitucional da liberdade ${ }^{11}$, consagrado, pelo art. $226, \S 7^{\circ}$ da $\mathrm{CF} / 88$ e como se pode extrair do dispositivo, dispõe sobre a liberdade no âmbito familiar no tocante a "livre decisão para o planejamento familiar", por isto, é um dos princípios que embasa o Direito de Família.

A legislação infraconstitucional dispõe sobre esse princípio no art. 1.513 do CC/02, com o reforço disposto no art. $1.565, \S 2^{\circ}$ do mesmo Código, pois como se extrai dos

\footnotetext{
${ }^{11}$ Contudo, entende-se que todos os princípios são fundamentais para subsidiar os estudos sobre o Direito de Família na contemporaneidade, mas devido ao próprio sentido do princípio da liberdade é necessário focar a análise no tema sobre liberdade, pois este compõe a principal sustentação da presente pesquisa.
} 
dispositivos, o primeiro, "proíbe interferências na comunhão de vida instituída pela família". E o segundo aduz que, "o planejamento familiar é de livre decisão do casal".

O princípio em questão se refere a liberdade de agir na vida privada, onde os indivíduos usufruem do seu poder de escolha com autonomia de acordo com sua vontade. $\mathrm{O}$ que implica em dizer que os indivíduos gozam de liberdade para constituir ou desconstituir uma entidade familiar, o que inclui formar o modelo familiar que melhor the aprouver, ou ainda administrar os bens que pertencem ao patrimônio familiar, bem como, escolher as diretrizes educacionais, culturais e religiosas para a educação dos filhos, sem a intervenção ou restrição do Estado ou de pessoa de direito privado, desde que respeitados o princípio da dignidade humana, que engloba a não violação da integridade física, moral e mental de qualquer pessoa humana (LÔBO, 2016, p. 118).

Para Flavio Tartuce (2017, p. 1227), “o princípio em questão mantém relação direta com o princípio da autonomia privada". Portanto, no âmbito do Direito de Família existe a expressão da autonomia privada por meio das escolhas que se faz, entre elas, o de escolher as pessoas para uma comunhão de vida (TARTUCE, 2017, p. 1227).

Vale ressaltar, que na contemporaneidade essa liberdade é atributo de todos os membros que constituem a família. Entretanto, isso nem sempre ocorreu, pois em tempos antigos a mulher casada não poderia dispor de escolhas no âmbito familiar, já que era juridicamente dependente do marido e não dispunha de poder sobre os filhos, pois estavam submetidos ao poder patriarcal. A mulher não possuía liberdade para desconstituir o casamento e nem para constituir família fora do matrimônio (LÔBO, 2016, p. 118).

Desse modo, percebe-se que as entidades familiares eram constituídas sob relações de poder e dominação do homem sobre a mulher, dos pais sobre os filhos (TARTUCE, 2018, p. 352). Contudo, como mencionado, houve uma evolução nos costumes e na organização social, que convergiram para o âmbito familiar. E muitas liberdades foram conquistadas pelas mulheres, entre elas, está a de exercer o poder familiar com igualdade de poderes. (LÔBO, 2016, p.118).

É imperioso mencionar que o Estado tem o dever de proteger a família, como se extrai do art. 226, $\S 8^{\circ}$ da $\mathrm{CF} / 88$, que prevê "a criação de mecanismos para coibir a violência no âmbito das relações familiares". A não intervenção do Estado no âmbito privado sob a óptica do Direito de Família engloba a proteção a outros princípios, como o da igualdade, 
convivência familiar, melhor interesse da criança e responsabilidade familiar, pois o Estado ao garantir essa proteção, protege direitos (TARTUCE, 2017, p. 1228).

Destarte, entende-se que o exercício da liberdade no âmbito familiar, envolve limites impostos por outros princípios que visam proteger a pessoa humana.

\section{A MEDIAÇÃO NO DIREITO DE FAMÍLIA E O PROTAGONISMO DAS FAMÍLIAS COM AS CONTRIBUIÇÕES DE PAULO FREIRE}

A mediação foi introduzida no Direito de Família com o intuito de proporcionar aos indivíduos, a resolução dos conflitos de forma autocompositiva, pelo consenso. E como, mencionado, a mediação preferencialmente deve ser utilizada em relações continuadas com o fim de preservar os relacionamentos. E no Direito de Família, essa proteção é fundamental, pois o cerne nesse ramo é a convivência humana. Ademais, conforme exposto, nessa área podem surgir conflitos decorrentes de relação de poder, como dominação, desrespeito e violências, pois apesar das liberdades conquistadas, os resquícios de relação de poder ainda persistem e concorrem com o afeto (TARTUCE, 2018, p. 352).

Dessa forma, entende-se que a mediação no Direito de Família não prescinde de um tratamento diferenciado, o que requer que a condução do procedimento seja realizada por um profissional com formação diferenciada, pois envolve o intuito de resolver o conflito, e ao mesmo tempo, preservar as relações humanas, que são movidas muitas vezes, por relações de poder, emoções e afeto. E ao mesmo tempo em que as preserva, pode proporcionar proteção a direitos e o exercício da autonomia da vontade e da liberdade (que são inerentes às relações familiares), trazendo responsabilidade aos indivíduos. Por isto, entende-se como muito pertinente a aplicação da mediação no Direito de Família, desde que a autonomia da vontade das partes e a liberdade sejam respeitadas (TARTUCE, 2018, p. 352).

Nesse sentido, se manifesta brilhantemente Rozane da Rosa Cachapuz (2011, p. 133) ao ilustrar que,

\footnotetext{
A mediação reconhece que as emoções são parte integral do processo de resolução e, como tal, devem ser atendidas, para que mais tarde não resultem em constantes ações revisionais, até porque os conflitos de casais, antes de serem de direito, na grande maioria são essencialmente emocionais.

Mediação de família é, em especial, um processo que enfatiza a responsabilidade dos cônjuges de tomarem decisões que vão definir suas próprias vidas, isolando
} 
pontos de acordo e desacordo e desenvolvendo opções que levam a uma nova tomada de decisões.

Analisando-se o conteúdo dos dispositivos legais que regem a mediação familiar, observa-se no art. 694, de onde se extrai, "todos os esforços serão empreendidos para a solução consensual", um fomento nas resoluções consensuais de conflitos, o que traduz uma preocupação em inserir a autocomposição nas ações de família, o que pode estimular o exercício da autonomia das partes, desde que não exista nenhum ato coercitivo para que as partes resolvam os conflitos de forma consensual (TARTUCE, 2018, p. 356).

Como se extrai do art. 695 do NCPC, o primeiro ato judicial no tocante a prática da autocomposição, se consubstancia quando, “o juiz ao receber a petição, se for o caso, e após tomadas todas as providências relativas a eventuais urgências, o réu será citado para comparecer à audiência de conciliação e mediação. Há quem entenda que este dispositivo obriga as partes a participarem da autocomposição, sendo, portanto, um dispositivo que contém regras distintas do que consta no procedimento comum, que admite a não obrigatoriedade da autocomposição (TARTUCE, 2018, p. 357-358).

No entanto, o presente estudo entende de forma diversa e acompanha o entendimento de Fernanda Tartuce (2017, p. 358) que afirma ser possível fazer uma "leitura alinhada às diretrizes regentes dos meios consensuais - sobretudo ao princípio da autonomia". Ademais, consta na regra, a expressão, "se for o caso", prossegue a autora Tartuce (2017, p. 358), "remeterá diretamente às exceções [...] presentes no art. 334, § $4^{\circ}$, que são [...] $]^{12 ” . ~ D e s s e ~}$ modo, entende-se que as partes já usufruirão dos princípios da autonomia e liberdade ao optarem ou não, pela realização da autocomposição, ou seja, inicia-se o protagonismo das famílias neste ato.

Constata-se que há autores, como Fernanda Tartuce (2018, p. 204), que defendem a ideia de que a mediação pode propiciar "aos participantes o poder de protagonizar o encaminhamento da controvérsia”. Observou-se que as autoras Zaparolli e Krähenbühl (2012, p. 89), defendem a ideia de que o "modelo transformativo idealizado por Folger e Bush pressupõe um aumento no protagonismo dos mediandos".

\footnotetext{
${ }^{12}$ Texto do $\$ 4^{\circ}$ do art. 334 do NCPC: " $\$ 4^{\circ}$ A audiência não será realizada:

I - se ambas as partes manifestarem, expressamente, desinteresse na composição consensual;

II - quando não se admitir a autocomposição".
} 
Desse modo, transportando-se essas ideias sobre a mediação para o Direito de Família, percebe-se que estas se coadunam com o princípio da liberdade existente no âmbito familiar. Por isto, entende-se que como adequada a ideia de que as famílias possam usufruir de oportunidades para exercerem o protagonismo no encaminhamento em suas escolhas no ambiente da mediação de conflitos, se o "modelo transformativo" for alinhado às práticas de mediação no Direito de Família.

Daí se identifica que as teorias de Paulo Freire podem contribuir para a prática da mediação no tocante ao protagonismo da pessoa humana, pois o autor aborda a ideia e que o indivíduo pode ser o agente ativo para transformar a realidade circundante por meio de suas decisões e ações.

Constatou-se que o âmbito familiar não está totalmente isento de conflitos decorrentes de relação de poder, que são resultado da dominação, que pode ocorrer, por exemplo, entre homens e mulheres. Nesse sentido, a mediação pode contribuir para que um conflito deste tipo possa ser trabalhado e transformado. Ao abordar esse tema, Águida Arruda Barbosa (2015, p. 131-132) esclarece que, "ademais, um conflito oriundo de questão de gênero pode ser facilmente transformado, desde que seja compreendido. E justamente essa dinâmica da mediação é possível encontrar o ponto de ajuste necessário para o acerto de sexo e poder $[\ldots] "$ ".

E, entende-se que nessa questão Paulo Freire (2014, p. 74 e 78), pode contribuir, pois expõe que a agressividade oriunda da opressão pode existir entre os iguais. E para superar isso, propõe a "ação libertadora" para que os indivíduos reflitam sobre a realidade, aceitem a luta e se "engajem" com suas decisões e ações que podem desmantelar a dominação e a injustiça.

Dessa forma, a "ação libertadora", proposta por Freire, pode contribuir para que a mediação no Direito de Família viabilize aos participantes oportunidades para que sejam protagonistas de seus destinos ao administrarem seus conflitos, o que pode lhes trazer também a superação da "autodesvalia", que é concebida por Freire (2014, p. 69), como uma visão de incapacidade que os oprimidos possuem de si mesmos, já que ao administrarem seus próprios conflitos, poderão perceber que possuem capacidades e poder. Nesse sentido, demonstra o relato de Paula de Magalhães Chisté (2018, p. 1340) que afirma, “[...], quando os mediandos recebem a informação de que o mediador não fará sugestões de acordo e que cabe a eles próprios gerar ideias de solução, eles se espantam com o poder que recebem”. 
Entende-se, pela definição e estrutura da mediação, que ao ser inserida no Direito de Família, o instrumento possui potencial para que as partes sejam protagonistas, podendo de forma conjunta exercer a liberdade, direcionar seus destinos e clamar pela proteção do Estado onde esta for pertinente e indispensável para proteger direitos, ou seja, as partes poderão ser protagonistas de seus destinos.

\section{CONSIDERAÇÕES FINAIS}

Como se pôde observar, o protagonismo da pessoa humana sob a óptica de Paulo Freire envolve os conceitos de liberdade e autonomia que o autor contextualiza numa cultura de dominação e opressão que existe na sociedade, onde ocorre uma relação de subjugação entre os opressores e os oprimidos. Os oprimidos são os dominados, são aqueles que não possuem liberdade e autonomia, são o "ser menos". Eles seriam por exemplo, os camponeses ou operários inseridos numa cultura de dominação. Entende-se que essa cultura pode estar presente na sociedade em vários âmbitos, expressando as características peculiares concebidas pelo autor, que são: a "dependência emocional" que causa a "dualidade existencial" e a "autodesvalia".

Paulo Freire propõe a superação dessa cultura de dominação por meio da "ação libertadora", que deverá enfrentar obstáculos, que são as características peculiares já mencionadas. Portanto, essa "ação libertadora" deverá se pautar na reflexão sobre a realidade com o fim de transformá-la. Ademais, deve-se antes de tudo "aceitar ou não a luta". E a superação da dominação se concretizará por meio do "da autonomia, que é condição para exercer a liberdade com ética". E esse protagonismo não se consubstancia somente para reivindicar necessidades básicas para a sobrevivência, mas para ser protagonista de sua história, desmantelando a ordem injusta.

Observou-se que a mediação foi positivada no Brasil e sua definição se destaca por ser um instrumento autocompositivo que permite o exercício da autonomia dos indivíduos ou partes envolvidas em um conflito, já que o mediador, que é quem conduz o procedimento, não possui poder decisório. Ademais, constatou-se que a mediação possui com um dos princípios norteadores, a "autonomia da vontade das partes".

Observou-se que a mediação utiliza suporte teórico interdisciplinar e possui uma estrutura que não lhe permite ser visto somente como um instrumento que possui como 
função resolver um conflito ou estabelecer um acordo. A mediação possui potencialidades, conforme constatou-se no modelo trazido por Folger e Bush com a "abordagem transformativa", que é o de propiciar "o aumento do protagonismo aos mediandos", pois nesse âmbito, as partes podem perceber-se como pertencentes ao conflito com capacidade para administrá-lo com autonomia.

Constatou-se que o Direito de Família é um ramo do Direto Civil que possui peculiaridades, pois é uma área que visa proteger fundamentalmente a pessoa humana. E foi apresentado que essa proteção ocorre por meio dos princípios constitucionais. O princípio da liberdade (enfoque do presente estudo), se refere a liberdade de agir no âmbito familiar da vida privada sem restrições do Estado, desde que haja respeito aos limites impostos pelos princípios constitucionais que visam proteger a pessoa humana.

Observou-se que a mediação de conflitos foi introduzida no Direito de Família de forma específica pelo NCPC. E que a mediação nessa área possui um trato particular, pois os conflitos decorrem de relações continuadas, decorrentes muitas vezes, não somente de afeto, mas também de relações de poder, o que demanda um tratamento interdisciplinar para garantir a proteção à pessoa humana, bem como, preservar as relações humanas primando pela pacificação, resolver o conflito e garantir a autonomia da vontade e o exercício da liberdade pelas partes. Por isto, conclui-se que a mediação possui importante pertinência ao Direito de Família, desde que se respeite a autonomia da vontade das partes, o exercício da liberdade e demais princípios constitucionais.

No tocante ao protagonismo das famílias e as possíveis contribuições de Paulo Freire denota-se que a mediação no Direito de Família pode proporcionar o exercício da autonomia e da liberdade com responsabilidade e ética, pois primeiramente, como pode-se observar, parte da doutrina e este estudo defendem a ideia de que as partes podem optar pela autocomposição. Entende-se que essa liberdade de opção se aproxima da ideia proposta por Paulo Freire que é a do exercício das decisões. E a responsabilidade, elemento defendido por Freire, se manifesta pelas decisões emitidas durante a autocomposição e representam o protagonismo das partes, ideia defendida também pela doutrina jurídica. E nesse trajeto, observa-se que o protagonismo não consiste somente no exercício das decisões individuais, mas também traz a responsabilidade com ética, pois as decisões realizadas em conjunto possuem limites embasados pelos princípios constitucionais. Ademais, observou-se que o protagonismo pode trazer a autovalorização, pois as partes se percebem como administradoras dos próprios 
conflitos com independência. E com isso traz a superação da "autodesvalia", conforme ideia concebida por Freire.

Portanto, conclui-se que a mediação no Direito de Família possui pertinência e que as concepções de Paulo Freire podem contribuir de forma abrangente para a aplicação da mediação de conflitos no Direito de Família visando o protagonismo das famílias fundamentado na concepção de que "a autonomia é condição para o exercício da liberdade com ética". E, que além disso, é de fundamental importância que se conjugue à ideia deste protagonismo, a concepção de que os envolvidos são sujeitos do processo com a possibilidade de propiciar às partes a superação da "autodesvalia" e dos efeitos advindos das relações de poder imiscuídas nas entidades familiares, desde que se respeite os princípios constitucionais e infraconstitucionais, permitindo a opção pela adoção da autocomposição, bem como, se alinhe a prática às diretrizes regentes e aos estudos teóricos embasados nos mesmos princípios e que exploram as potencialidades da mediação, dentre eles, o modelo proposto por Folger e Bush, que oferecem suportes aos trabalhos autocompositivos concernentes a mediação.

\section{REFERÊNCIAS}

ARENDT, Hanna. Homens em tempos sombrios. (s.1.): Companhia das Letras, [20--?]. Ebook.

BARBOSA, Águida Arruda. Mediação familiar interdisciplinar. São Paulo: Atlas. 2015.

BRASIL. [Constituição (1988)]. Constituição da República Federativa do Brasil de 1988. Brasília, DF: Senado Federal, [2019]. Disponível em:

https://www2.senado.leg.br/bdsf/bitstream/handle/id/518231/CF88_Livro_EC91_2016.pdf. Acesso em: 28 jul. 2019.

BRASIL. Código de Processo Civil. Instituído pela Lei n. 13.105 de 16 de março de 2015. Brasília, DF: Presidência da República, [2019]. Disponível em:

http://www.planalto.gov.br/ccivil_03/_ato2015-2018/2015/lei/113105.htm. Acesso em: 16 ago. 2019.

BRASIL. Lei n. 13.140 de 26 de junho de 2015. Dispõe sobre a mediação entre particulares como meio de solução de controvérsias [...]. Brasília, DF: Presidência da República, [2019]. Disponível em: http://www.planalto.gov.br/ccivil_03/_ato2015-

2018/2015/Lei/L13140.htm2018/2015/lei/113140.htm. Acesso em: 10 mar. 2019.

BRASIL. Lei 10.406 de 10 de janeiro de 2002. Institui o Código Civil. Brasília, DF:

Presidência da República, [2019]. Disponível em:

http://www.planalto.gov.br/ccivil_03/leis/2002/110406.htm. Acesso em: 16 ago. 2019. 
BRASIL. Conselho Nacional de Justiça. Resolução n. 125/2010, de 29 de novembro de 2010. Dispõe sobre a Política Judiciária Nacional de tratamento adequado dos conflitos [...]. Brasília, DF: Conselho Nacional de Justiça, 2010. Disponível em: http://www.cnj.jus.br/images/stories/docs_cnj/resolucao/Resolucao_n_125-GP.pdf. Acesso em: 18 jul. 2019.

CACHAPUZ, Rozane da Rosa. Mediação nos conflitos e direito de família. Curitiba: Juruá, 2011.

CALMON, Petrônio. Fundamentos da Mediação e da Conciliação. 2. ed. Brasília, DF: Gazeta Jurídica, Forense, 2013.

CHISTÉ, Paula de Magalhães. A reação dos mediandos pelo olhar dos mediadores.

[Depoimento cedido a] Adolfo Braga Neto. In: BRAGA NETO, Adolfo (org.) Mediação familiar: a experiência da $3^{\text {a }}$ Vara [...]. São Paulo: Cla Cultural, 2018, p. 1340-1340. E- book.

FOLGER, Joseph. P.; BUSH, Robert A. Baruch. Mediação transformativa e intervenção de terceiros: [...] . In: SCHNITMAN, Dora Fried;LITTLEJOHN, Stephen (org.).Novos paradigmas em mediação. Chagrin Falls: Taos Institute Publications, 1999, p. 85-100. Ebook.

FREIRE, Paulo. Educação como prática da liberdade. Rio de Janeiro: Paz e Terra, 1967.

Pedagogia do oprimido. 56. ed. Rio de Janeiro: Paz e Terra, 2014.

Pedagogia da autonomia. 15. ed. São Paulo: Paz e Terra, 2000.

GARCEZ, José Maria Rossani. Negociação, ADRS, mediação, conciliação e arbitragem. 2 ed. Rio de Janeiro: Lumen Juris, 2004.

HIRONAKA, Giselda Maria Fernandes Novaes. O conceito de família e sua organização jurídica. In: PEREIRA, Rodrigo da Cunha (coord.). Tratado de direito das famílias. 2. ed. Belo Horizonte: IBDFAM, 2016. p. 27-100.

HOUAISS, Antonio; VILLAR, Mauro de Salles; FRANCO, Francisco Manoel e Mello. Dicionário Houaiss da língua portuguesa. Rio de Janeiro: Objetiva, 2009.

KAMII, Constance; DECLARK,Georgia. Reinventado a aritmética: implicações da teoira de Piaget. 2. ed. Campinas: Papirus, 1988.

LÔBO, Paulo. Direito de família e os princípios constitucionais. In: PEREIRA, Rodrigo da Cunha. (coord.). Tratado de direito das famílias. 2. ed. Belo Horizonte: IBDFAM, 2016. p. 103-131.

MONTEIRO, Washington de Barros; SILVA, Regina Beatriz Tavares da. Curso de direito civil: direito de família. 43. ed. São Paulo: Saraiva, 2016. 
OLIVEIRA, Virginia Grace Martins de. A conciliação e a mediação extrajudiciais no Brasil [...]. Orientador: Adriana Silva Maillart. 2015. 118 f. Dissertação (Mestrado em Direito) - Programa de Mestrado em Direito, Universidade Nove de Julho, São Paulo, 2015.

TARTUCE, Fernanda. Mediação nos conflitos civis. 4. ed. São Paulo: Método; Rio de Janeiro: Forense, 2018.

TARTUCE, Flavio. Manual de direito civil. 7. ed. São Paulo: Método; Rio de Janeiro: Forense, 2017.

ZAPPAROLLI, Célia Regina; KRÄHENBÜHL, Mônica Coelho. Negociação, mediação, conciliação, facilitação assisitida, prevenção, gestão de crises [...] São Paulo: LTr, 2012. 